\title{
Extending Holt's (1995) Typology to Encompass Subject-Subject Relations in Consumption: Lessons from Pet Ownership
}

\begin{abstract}
This paper adapts Holt's (1995) typology of consumption practices to illuminate consumption practices within the context of British consumers and their household pets. The photo-elicitation technique, autodriving is used to elicit stories from our participants concerning their cats and dogs. Holt's typology provides a strong foundation for illuminating the consumption practices described in these stories. However, in order to capture the cultural meanings and social dynamics that animate these consumption practices more fully we propose extending Holt's framework so as to incorporate (1) the agency of the animal, (2) the incidence of literal play, and (3) the moral values underlying consuming-asclassification. The paper concludes with a discussion on the value of our proposed additions in relation to future cultural studies of human-animal relations and to future cultural studies of consumption in general.
\end{abstract}

Keywords: $\quad$ consumption practices; pets; companion animals; consumer-object relations; agency; play; moral values.

\section{Introduction}

The UK pet market has witnessed significant growth over the last 5 years. However, compared to the USA, British academic interest in consumers and their household pets is less evident, especially from a consumption-based perspective. This is despite the fact that a greater understanding of human-animal relationships may lead to important insights toward a better understanding of ourselves (Arluke 2003; Cavanaugh, Leonard and Scammon 2008; Sanders 2003), and ourselves as consumers in particular (Aylesworth, Chapman, and Dobscha 1999). Moreover, as Brownlie $(2008,523)$ has argued previously "the companionship between humans and animals is a potentially rich consumption context by means of which to advance consumer culture theory".

Many studies on consumption use the term consumption object, which is broadly construed as a product, service, person or experience and could presumably also include a household pet. However, we believe that assigning the term consumption object to household pets is rather problematic. As Hirschman $(1994,624)$ cogently argues, pets constitute a "mediating category between humans and animals, having aspects of both but being fully neither one or the other". The liminal position of pets between animals and humans is 
demonstrated in the use of the term "companion animal" by some authors (see Hirschman 1994; Holbrook et al. 2001; Holbrook and Woodside 2008) and the continued use of the term “pets” by others (see Belk 1996; Beverland, Farrelly and Lim 2008). In defense of his stance, Belk (1996, 122) argues:

\footnotetext{
"I realize that pets is no longer a politically correct term and that companion animals is more in vogue... Yet these animals, even when we treat them as quasi-human equals, did not freely choose to be with us...Keeping the term pets recognizes this hierarchy of ownership...the pets versus companion animals metaphors reveal the dual ways in which we regard and treat these animals".
}

Thus, we adopt the position advanced by Zwick and Dholakia who define objects "very broadly as non-human entities, which includes animals" $(2006,39)$.

We recognize the recent contribution to the human-animal and pet ownership literature made by Holbrook and Woodside’s (2008) special issue on “Animal companions, consumption experiences and the marketing of pets: Transcending boundaries in the animalhuman distinction". Also acknowledged are the previous studies that have developed theory in the areas of: pets and the self-concept or identity (Belk 1988, 1996; Greenebaum 2004; Sanders 1990, 2003); our relationships with companion animals (Harker, Collis and McNicholas 2000; Holbrook 1996); sociability and well-being (Hirschman 1994; Wood, Giles-Corti and Bulsara 2005); and companion species consumption (Haraway 2003). However, we suggest that Holt's (1995) Typology of Consumption Practices may be usefully adopted to revisit the context of pet ownership in order to further illuminate the consumption practices therein.

Holt's (1995) framework focuses attention on consumption as a form of "social action". He borrows the concept of "practice" from social theorists such as Bourdieu and Foucault, which as he explains more fully in a later study helps "to emphasize that human actions are not merely physical behaviors disconnected from thoughts (as the term "consumer behavior" is often used) but, rather, have meanings embodied in them" (Holt 1997, 333). Indeed, Warde $(2005,144)$ suggests that "If the individual is merely the intersection point of 
many practices, and practices are the bedrock of consumption, then a new perspective on consumer behaviour emerges". Thus, the key contributions of Holt's (1995) typology for consumer research lie in his focus on consumption practices and his demonstration of the ways in which consumers draw on cultural frameworks in order to make sense of their experiences.

There are some similarities between Holt's (1995) Typology of Consumption Practices and Holbrook's $(1994,1999)$ Typology of Consumer Value ${ }^{1}$ in that both typologies analyze consumer value in use (Peñaloza and Venkatesh 2006). Holbrook $(1999,5)$ defines consumer value as "an interactive relativistic preference experience", which typically "refers to the evaluation of some object by some subject". His framework is organized around three taxonomic dimensions (i.e. self-oriented/other-oriented; active/reactive; extrinsic/intrinsic) and identifies eight types of value that subjective evaluation might comprise namely, efficiency; excellence; status; esteem; play; aesthetics; ethics; and spirituality. Holt's (1995, 1) typology also focuses on "the variety of ways in which consumers interact with consumption objects". He argues similarly that the meaning of consumption is underdetermined by the characteristics of the consumption object. Indeed, Holt (1995) draws on some elements of Holbrook's (1994) taxonomic dimensions, although he develops his typology of consumption practices around only two dimensions; namely the structure and purpose of consumption (we will discuss these two dimensions in the next section).

We begin this paper by drawing on the literature relating to human-animal relations together with Holbrook's (1999) taxonomic dimension of “active versus reactive”. This allows us to develop Holt's (1995) framework so as to incorporate the liminality of the household pet as both consumption object and non-human subject. Following this, we discuss the photoelicitation technique that we used to 'drive' 'long interviews' (McCracken 1988) with participant dog and cat owners. Our ensuing analysis highlights the distinct value in utilizing photographs to help reveal in greater depth, "profound layers of consumption-related 
meanings" (Holbrook 1997, 218). The contribution of this article is twofold; first, we propose extensions to Holt's (1995) typology and assess the re-worked typology empirically so as to investigate "the cultural meanings, socio-historic influences, and social dynamics that shape consumer experiences" (Arnould and Thompson 2005, 875) with household pets. Second, we contribute to current knowledge on the experiential and socio-cultural practices concerning pet ownership. In so doing, we shed light on the agency of pets, the nature of play and the moral values underpinning pet ownership. Finally, we highlight the implications of these findings for future cultural studies of human-animal relations, and for future cultural studies of consumption more generally.

\section{Evaluating Holt's (1995) Typology of Consumption Practices in the Context of Pet Ownership}

As Figure 1 shows, Holt $(1995,1)$ categorizes consumption practices in a typology organized around the structure of consumption and the purpose of consumption. The structure of consumption refers to the ways in which consumers engage directly with consumption objects as well as the ways in which these objects provide a focus for interacting with other people. With regard to the purpose of consumption, Holt suggests that consumers engage in activities that are at one and the same time autotelic and instrumental. That is, activities that serve both as an end in themselves and as a means to an(other) end.

(Figure 1)

Taken together these dimensions are represented by the following four metaphoric meanings of consumption: (1) 'Consuming as experience': (2) 'Consuming as integration'; (3) 'Consuming as classification' and 'Consuming as play'. Holt draws the first three of these four metaphors from the consumer research literature, and uses his case study of baseball 
spectatorship to refine these perspectives and to identify and develop the fourth metaphor of consuming as play. His framework has been used to examine a variety of consumption contexts including financial services (Allen and McGoun 2000), wine consumption (Groves, Charters and Reynolds 2000) and consumption at Christmas (McKechnie and Tynan 2006). In the following sections, we analyze the extent to which Holt's four metaphors and the ten consumption practices, in which they are embedded, enhance our understanding of the experiential and socio-cultural practices surrounding pet ownership.

\section{Consuming as Experience}

Holt (1995) suggests that the consuming-as-experience metaphor clearly underpins previous research examining consumers' emotional responses to consumption objects. His analysis contributes to the consuming as experience metaphor by adding a sociological dimension that identifies three consumption practices in which these emotional states are embedded, namely accounting, evaluating, and appreciating practices.

Accounting practices allow consumers to draw on an institutional interpretive framework in order to make sense of the consumption experience and involve typifying "actions and objects, assigning them specific meaning and value", and then contextualizing "this account by making connections with relevant facts to create a richer understanding" (Holt 1995, 5). In the context of pet ownership, consumers often draw on advertising and television sitcoms featuring animals which fuel "the association of goods and services with particular cultural meanings and values" (McFall and Du Gay 2002, 75). Herzog, Bentley and Hahn (2004) suggest that successful films portraying animals can dramatically alter the shift in the popularity of dog breeds. This was most definitely apparent in the rise of Dalmation dog owners in the UK during the 1990s, when Disney's film '101 Dalmations' became the $14^{\text {th }}$ highest grossing film in the UK (AC Neilsen EDI, 2007). 
Evaluating practices allow consumers to apply this institutional interpretive framework in order to construct value judgments "on the situations, people and actions they encounter" (Holt 1995, 5). In addition to advertising, television sitcoms and films, the institutional frameworks used to assist UK consumers in making value judgments on dogs and cats may be drawn from the Kennel Club (est. 1873) and the Governing Council of the Cat Fancy (est. 1910). As the practice of "evaluating involves comparisons to three types of baselines: norms, history and conventions" (Holt 1995, 5), other institutional frameworks such as registered breeding clubs for specific breeds are also credited with providing 'breed standards' information. To give an example of their presence in the UK, eight registered breeding clubs exist for the Scottish terrier alone - a dog breed which does not even feature in the Top 10 preferred breeds in the UK. Nowhere are evaluating practices more evident than the world of dog and cat-shows.

There is a plethora of evidence relating to consumers' emotional engagement with their companion animals. In the first instance, many academics acknowledge the "unconditional love" that can exist between humans and their companion animals (Bettany and Daly 2008; Greenebaum 2004; Hirschman 1994; Holbrook 1996; Holbrook and Woodside 2008; Holbrook et al. 2001). These feelings of love can be instantaneous for both humans and animals as a participant in one study reveals: "I went in and immediately he came right over to me. It was love at first sight - he chose me" (Sanders 2003, 417). Holbrook also adds that "you do not choose a cat; rather a cat chooses you" $(1996,148)$. Secondly, a number of studies suggest that many view their pets as a friend; family member; or a substitute for a child/“fur-baby”, parent or partner (Belk 1988; Greenebaum 2004, 117; Hirschman 1994; Sanders 1990). This emotional connection between humans and animals is evident in a range of appreciating practices such as owners regularly allowing their pets to share their bedrooms, buying their pets Christmas presents and celebrating their pets' birthdays (Greenebaum 2004; Hirschman 1994). 
While our analysis indicates that consumers' emotions are embedded in a number of accounting, evaluating and appreciating practices, the above discussion suggests that animals respond emotionally to humans and this implies a level of reciprocity between animals and humans that is not easily captured by Holt's consuming as experience metaphor.

Consequently, since Holbrook et al. suggest that "what makes animals special...is their potential to be like us and for the categorical boundary between humans and animals to be blurred" $(2001,2)$, we advocate a "closer examination of the extension of social processes beyond species boundaries" (Myers 2003, 47). Certainly, a number of academics working from a post-humanist perspective within cultural studies, feminist research, sociology, science studies and more recently, consumer research have theorized the blurring of boundaries between humans and non-humans, nature and culture, subjects and objects (see Arluke 2003; Bettany and Daly 2008; Callon 1986; Fox 2006; Haraway 2003; Holbrook and Woodside 2008; Peñaloza 2008; Sanders 2003; Taylor 2007). Thus, we would suggest that the consuming-as-experience metaphor needs developing in order to capture the reciprocity of household pets and the co-construction of emotional experience.

\section{Consuming as Integration}

Consuming as integration "describes how consumers acquire and manipulate object meanings" (Holt 1995, 2). The metaphor refers to the assimilating, producing and personalizing practices "used by consumers to enhance the perception that a valued consumption object is a constitutive element of their identity" (Holt 1995, 6).

Assimilating practices refer to the methods by which consumers become competent within a social world of consumption practices, thus, re-orienting the self-concept to align with a particular identity. With regard to pet ownership, key facets of assimilation include being able to demonstrate a sufficient level of competence. That is, "thinking like, feeling like... and looking like" a competent pet owner "so that enacting the role" of pet owner 
“becomes taken for granted" (Holt 1995, 7). Manifestations of these practices include owners' efforts to develop their knowledge relating to their pets' behavior and welfare. Despite the many benefits associated with dog training (e.g. improved obedience, fewer behavioral problems), Bennett and Rohlf (2007) indicate that few owners attend obedience classes, preferring to opt for home-based training via books, videos, and conversations with friends or family.

While assimilating practices operate to reorient the self-concept to align with a particular identity, producing and personalizing practices serve to draw objects symbolically into one's self-concept. Holt (1995) refers to this latter set of integrating practices as selfextension processes. Belk (1988) suggests that the aphorism "love me, love my pet" provides at least some indication that pets are often seen as part of the owner's self. However, Ahuvia suggests that since Belk's (1988) original work on the extended self, consumer research on identity has evolved to conceptualize the self as "narrative", and that this has led to an increased focus on the nature of identity construction. Thus, Ahuvia $(2005,179)$ asserts that "like all metaphors, the framing of identity as consisting of a core versus extended self both illuminates and obscures". As a result, this tends to draw attention to self-expression while obscuring self-transformation or the transformative power of possessions. He goes on to argue that:

"Much of the difficulty with the core-self metaphor arises from the image of the core self "reaching out," as it were, to expand itself by incorporating a new object. This can give rise to the idea that the core self is prior to, and ontologically distinct from, the extended self" (2005, 180).

Focusing on the context of human-animal relations, a number of sociologists' findings resonate with those of Ahuvia (2005); see for example, Sanders (1990). However, Taylor $(2007,1)$ argues that "the inclusion of human-animal relationships into the "social" sciences has, at its heart, far more radical and theoretical potential than is first apparent" for this "leads logically to an erosion of the Cartesian dualisms upon which the vast majority of social (and 
indeed general) thought is based". She proposes that an alternative to this conception is to see animals and humans as inter-subjectively constituted which is to acknowledge the subjectivity of the animal and its reciprocal role in the human-animal relationship (see also Haraway 2003). Working from the same perspective as Haraway (2003) and Taylor (2007), Bettany and Daly $(2008,411)$ develop the term "hearthound" in order to exemplify the intersubjective construction of the identity of Afghan hound owners and their dogs, asserting that "the hearthound is not an extension of self but is co-extensive with the self". Similar arguments regarding the subjectivity and hence agency of consumption objects have been made by Borgerson (2005), Firat and Dholakia (1998), and Holbrook (1999). Further support can be found in Zwick and Dholakia $(2006,32)$ who draw on Knorr Cetina $(2001,163)$ to assert that consumers relate to objects "not only as 'doers' and 'accomplishers' of things within an agency framework but as experiencing, feeling, reflexive, and remembering beingsas bearers of the sort of experiences we tend to reserve for the sphere of intersubjective relationships".

Holt's (1995) consuming-as-integration metaphor and the consumption practices in which this is embedded, help to shed light on the instrumental aspects of identity construction. However, Zwick and Dholakia (2006, 31) argue that while "consumer-centric conceptualizations remain important in deepening our understanding...they are no longer sufficient to grasp the nature of consumer-object/brand relationships". Thus, we propose that the consuming-as-integration metaphor needs extending in order to capture the subjectivity and transformative power of companion animals and hence the inter-subjectivity of identity construction.

\section{Consuming as Play}

Holt $(1995,3)$ considers this autotelic dimension to be "an important aspect of consuming" since it captures the consumer's use of consumption objects "as resources to 
interact with fellow consumers" whereby the interaction "has no ulterior end, [just] interaction for interaction's sake" (Holt 1995, 9). Consequently, he identifies two types of playing practices that he observed at the baseball games - namely, communing and socializing. In communing, "spectators share their mutually felt experiences with each other, and in socializing, spectators make use of experiential practices to entertain each other" $(1995,9)$.

Similar to Holt's $(1995,9)$ observation in the context of a baseball game, pets often facilitate interaction among individuals who "have few other commonalities" (Sanders 1990, 2003; Wood, Giles-Corti and Bulsara 2005). One explanation for such interaction is that "pets can serve as an ice-breaker and a neutral topic for conversation" (Dotson and Hyatt 2008; Wood et al. 2007, 47). Indeed, for many owners the actual acquisition of a pet "represents a desire to extend existing networks of relationships" (Harker, Collis and McNicholas 2000, 206). Interestingly, although cats often facilitate private social interaction within the family home and between neighbors (Laurier, Buckner and Whyte 2002), both public and private social interaction via pets is more commonly noted amongst dog owners (Wood, Giles-Corti and Bulsara 2005).

The family home, public parks and neighborhoods all provide an opportunity for pet owners to commune and to socialize in that they are able to share their emotional experiences of living with their companion animals with both the acquainted and unacquainted (Dotson and Hyatt 2008; Wood, Giles-Corti and Bulsara 2005). Commercial businesses such as "Doodley Dogs" (UK indoor play park facilities for dogs) and "Fido's Barkery" (US bakery which sells treats for dogs) also offer opportunities for communing and socializing practices and help to create long-lasting friendships between both dogs and owners (Greenebaum 2004). Doodley Dogs for example, provides flyball and agility facilities for dogs to perform or compete, thus enabling owners to use such experiences "as a means to socialize" (Holt 
1995, 10). Similar socializing practices are also evident at dog and cat shows as evaluations of breeds and humorous comments are used by spectators and owners to entertain each other.

Holt's metaphoric use of the term "playing" is clearly appropriate in the context of professional baseball, where it was identified $(1995,9)$. Indeed, using play as a metaphor in the context of consumers and their household pets is particularly appropriate since "playing" immediately brings to mind the scenario of consumers playing literally with their pets. Sanders argues that "mutual play is a central mode of interaction between people and their nonhuman friends" $(2003,414)$. Moreover, the presence of a dog reminds some owners of the “importance of frolicking and play" (Stephens and Hill 1996, 209). Similarly, Holbrook et al. $(2001,6)$ reflect on the "infectious playfulness" of companion animals and the "personal enrichment" gained from engaging "more spontaneously in childlike games or playful activities”. Rooney, Bradshaw and Robinson (2000) point to another dimension of play - play between animals. They compare animal-human play with animal-animal play and find that reciprocal play between animals and humans is less competitive than play between animals. For example, the animal is "more likely to give up on a competition, to show and present the toy to their play partner" (325). While the reciprocal play between humans and animals does not preclude human (consumers) interacting with other humans, neither does it necessarily involve engaging with other humans.

Although Holt's (1995) consuming-as-play metaphor highlights the relevance of social interaction, the practices of communing and socializing apply to the human interaction surrounding pets, but do not address the literal and reciprocal nature of play between a human and his or her pet nor play between pets. We therefore suggest that this metaphor requires developing in order to incorporate these additional aspects of play.

\section{Consuming as Classification}


Holt $(1995,10)$ refers to Mick and DeMoss (1990) to establish that "consumers classify by leveraging their interaction with the object - their experiential and integrating practices - to communicate with other consumers". Classifying practices simultaneously "build affiliation" and “enhance distinction" (Holt 1995, 10). Holt (1995, 11) demonstrates that both can be achieved either via: the objects themselves, (where "the particular meanings associated with a consumption object provide the content of the classificatory act"); or through actions (where "object meanings are irrelevant - what matters is how one interacts with the object").

With regard to classifying via the consumption object itself, attempts both to augment affiliation and to increase distinction among pet owners may be fulfilled via the selection and display of specific breeds, hybrids or mongrels. Despite not being recognized by the UK Kennel Club (for dogs) or The Governing Council of the Cat Fancy (the UK's feline equivalent to the Kennel Club), there is increasing interest in hybrids (or designer breeds) such as the Labradoodle (a cross between a Labrador and a Poodle); the Cockapoo (a cross between a Cocker spaniel and a Poodle); the Ashera (a cross between an African serval and an Asian leopard cat); and the Toyger (a cross between the Bengal and a domestic shorthair cat).

Beverland, Farrelly and Lim $(2008,490)$ note that the consumption of designer hybrids is "indicative of a society that loves labels", especially given the high premiums paid for these hybrids. Consistent with Holt's (1995) assertion that objects and/or actions (i.e., how one interacts with the object) serve to classify consumers, a range of consumption practices serve to further distinguish the pet owners in their study. While Beverland, Farrelly and Lim's $(2008,492)$ extrinsically motivated participants engage in dressing up and pampering their dogs, the intrinsically motivated owners "do not ply their dogs with expensive toys or gifts... and dog clothes" because such items "represent an imposition of human standards and desires on the animal." They suggest that although the latter "recognize the dependent relationships pets have with their owners (for food, love and shelter), these participants 
believe strongly in the dogs' need to self-determine and are contemptuous of those who own pets for purely selfish reasons", such as those people who "get one for the image of the dog because it adds to their image" (492). On the subject of image, shopping for pet clothes has clearly become a popular pastime for some pet owners. Designers such as Ben de Lisi and Vivienne Westwood now offer couture fashion lines for dogs. Harrods - perhaps the most prestigious department store in the UK also hosts an annual dog-fashion show (see http://www.dogcentral.info/pet-porter-harrods-fashion-show/). Hirschman (1994) suggests that the dressing up and excessive grooming of companion animals is consistent with a desire for status or self-esteem and/or as a means to attract attention, sometimes known as the "dark side of human-animal relationships" (Arluke 2003, 33).

Finally, Holt asserts that "display is an incomplete description of how people communicate through objects" $(1995,10)$. He argues that this is particularly so for baseball spectators for whom the consumption object itself (game of baseball) is not a material object. Thus, baseball spectators have adopted a number of practices to enhance their ability to communicate their affiliation and distinction beyond the temporality of the game itself such as taking photographs. That said, he acknowledges that photographs can be relatively ambiguous and need to be accompanied by story-telling. We believe that this could also be true for pets, as owners are not always able to display their pets through their physicality. This is particularly relevant to cat owners as they do not generally walk their cats. Thus, many pet owners carry photographs of their pets and/or engage in storytelling about their pets.

Holt's (1995) metaphor of consuming as classification provides a useful perspective for examining the classifying practices of pet owners, both in terms of inferences made in respect of the choice of pet as well as the ways in which people interact with their pets. However, we feel that the consuming as classification metaphor misses something of clear significance in the context of pets compared to that of baseball - namely, the moral dimensions of classifying practices such as the dressing-up and excessive grooming of pets. In 
their analysis of consumers' motivations and meaning creation, Heisley and Cours (2007) identify four socio-cultural motivations, which are instructive here. These comprise "connectedness" and three types of "worthiness", namely prestige, status and values. Comparing Holt's (1995) framework with that of Heisley and Cours (2007), we would suggest that the consuming-as-classification metaphor appears to include worthiness related to prestige and to a lesser extent worthiness related to status. Moreover, Holt's (1995) notion of affiliation would seem to accord with their concept of connectedness. However, the consuming as classification metaphor does not embrace worthiness allied to personal, social or cultural values (i.e. morality in its broadest sense).

Since our analysis highlights potential opportunities for re-working specific aspects of Holt's (1995) typology in order to illuminate consumption practices in this context more fully, we decided to explore these consumption practices empirically. The next section describes the methodological approach that we adopted to elicit stories from our participants concerning their cats and dogs.

\section{A Photo-elicitation Approach}

Our approach draws on methods from visual anthropology and utilizes a technique known as autodriving (Heisley and Levy 1991). Autodriving describes a particular photo-elicitation technique (Collier 1967) whereby visual and/or audio recordings of informants are made by the researcher and then used as projective devices for interviewing (Prosser and Schwartz 1998). Heisley and Levy $(1991,260)$ suggest that "to a certain degree, autodriving allows informants to interview themselves... and to raise issues that are significant to them".

We wanted our participants to lead the way in order that we might understand the experiential and socio-cultural practices surrounding human-animals relations from their perspective. Therefore, following Zaltman and Coulter (1995) and Holbrook et al. (2001), our participants took their own photographs. We offered each participant a disposable camera; or 
if they preferred, and most did - they could use their own digital cameras to take photographs of their pets in whatever way they wished. We initially contacted four people known to us as friends and neighbors or work colleagues to ask if they would be willing to take part in our study. Thus, our initial convenience sample of four snowballed to a total of fifteen ${ }^{2}$. We then invited our participants to use these photographs to tell stories about themselves, their families, and their pets. Our interviews followed what Thompson, Locander and Pollio (1989) call the phenomenological interview. As Thompson, Locander, and Pollio (1989) suggest with the exception of the opening question, our interviews had no a priori questions concerning the topic. With permission from the participants, interviews were audio-taped and lasted from one to three hours. The verbatim transcripts were then independently and jointly reviewed by the two authors to identify consumption practices in this context.

\section{Re-working Holt's (1995) Typology to Incorporate Object Agency, Literal Play and Moral Values}

The photographs played a key role in stimulating participants to tell stories about their pet's character and behavior as well as supporting information about their pet's name(s), breed(s) and age(s). A total of thirteen pets (eight cats and five dogs) were currently owned by the fifteen participants.

\section{Pet Ownership as Experience: Reciprocal Love}

As expected all three of Holt's experiential practices, namely accounting, evaluating and appreciating were substantiated in the context of pet ownership. However, one theme running through many of the stories recounted by our participants that is not encapsulated by Holt's consuming-as-experience metaphor is that of a reciprocal loving relationship between owners and their household pets. Similar to the findings of Sanders (2003), feelings of love occurred instantly for some participants. For example, Claire described her reaction to meeting "Angus" for the first time as an overwhelmingly powerful experience - "I was like 
aah, I want the dog...It was like love at first sight...it was absolutely incredible”. In agreement with Holbrook (1996), albeit that he was referring to cats, Judith felt that the decision to select her dog was out of her control: “Once I'd seen her [Tessa], I felt like she'd kind of chosen me". Nathan suggested that "It's the whole thing...it's the whole cliché...it's the whole unconditional love”. Finally, Megan refers to one of her photographs which demonstrates how unusually devoted her cat Billy is to her as he follows her "absolutely everywhere...he would jump up on the worktop just to get closer to me...you are always falling over him...he's like 'where we going' y' know (laughs)... its quite endearing really” (Appendix 1a). These excerpts would seem to corroborate Holbrook and Woodside's (2008, 377) comment that "creatures give unconditional love in return".

As indicated in the earlier section on consuming as experience, Holt's (1995) typology does not allow for the consumption object to reciprocate in any fashion. However, Holbrook's $(1994,1999)$ framework does. This is elucidated by Holbrook via his "active versus reactive" taxonomic dimension; the active end of which "involves things done by a consumer to or with a product as part of some consumption experience" $(1999,11)$. Conversely, drawing upon Hall $(1961)$ the reactive end of Holbrook's $(1999,11)$ dimension “involves things done by a product to or with a consumer as part of some consumption experience. Here, rather than I (the subject) doing something to it (the object), the situation is reversed: It acts upon me or it moves $m e "$.

We would therefore suggest incorporating Holbrook's $(1994,1999)$ "active versus reactive" dimension within Holt's (1995) typology, albeit that we would argue that this is best captured via the following two dimensions: subject-object relations and subject-subject relations. Although Holbrook suggests that the active/reactive dimension can be thought of as "potentially continuous" $(1999,12)$, for the purposes of constructing his typology of value he treats this dimension as a dichotomy hence his use of the label "active versus reactive". This enables him to identify both active (i.e. efficiency; play; status; ethics) and reactive (i.e. 
excellence; aesthetics; esteem, spirituality) types of value. However, we see little merit in separating Holt's (1995) metaphorical meanings of consumption out into active and reactive constituents. Instead, we are asserting that these metaphorical meanings of consumption ought to embrace both subject-object (active) and subject-subject (reactive) relations (see Figure 2).

(Figure 2)

One consequence of the reciprocal loving relationship between humans and animals is that - consistent with Belk $(1996,2)$ - "pets are also commonly seen as humans". As identified by a number of other studies (Belk 1988; Greenebaum 2004; Hirschman 1994; Sanders 1990), many of our participants discussed their relationships with their pets as being similar to that of a partner and/or a family member, including their role as a child substitute. For example Judith suggested that Tessa was her "boyfriend substitute...that was how it was till you [referring to Nathan] came on the scene...then she had a step-daddy”. Millie mentioned talking to her cats "probably the way you might talk to another family member", and Alison informed us that her and her husband "had Patsy before Alex...Patsy was really the child substitute... she's a big part of our family”.

A further example of the similarity of pets and children came from Nathan, who in the context of discussing the scenario of having to leave Tessa with someone else, admitted to feeling guilty - “you have a kind of feeling that we can't farm her out...like bad parents”. However, it is interesting to note that at a different point in the conversation Nathan suggested that "I was never bothered about having children...so this is a great halfway house or substitute". Here, Nathan's comments seem to lend support to Hirschman's assertion that "pets reside in an intermediate position between nature and culture" $(1994,623)$. On the one hand, pets are anthropomorphized as in the extracts above, thus placing them close to human culture. On the other, there are many instances when our participants view their pets as 
animals, often drawing on "various interpretations of popular animal psychology that naturalize ideas of 'instinct' or animal behaviour" (Fox 2006, 527) to do so. Drawing implicitly on the popular animal psychology view that it is important to teach a dog its place in the pack, Mandy said that "one of the reasons I don't want her sleeping on the bed or sleeping in the bedroom is that she's got to know her place". Similarly, Jane suggested that "there's lots of talk about how the dog should be at the bottom... you should never feed your dog first - they should be fed after you".

Other examples of participants treating their pets more like animals than humans is in setting access boundaries around the house. In this regard, Claire informed us that her dog Angus is "not allowed upstairs at all". In relation to DJ his cat, Simon stated that "when we are out, all the bedroom doors are shut and the door to the conservatory is shut...so he doesn't have the run of the house".

Our critical and reflexive analysis of Holt's consuming-as-experience metaphor suggests that it both illuminates and obscures "the cultural meanings, socio-historic influences and social dynamics that shape consumer experiences" (Arnould and Thompson 2005, 875) with their household pets. With regard to the ways in which this metaphor obscures the social dynamics between owners and their pets, the above findings reveal that in addition to human subjects engaging emotionally with animal objects, there is clear evidence of animal agency (i.e. animal subjects engaging human subjects on an emotional basis). Thus our participants oscillate between talking about their pets as humans and referring to them as animals (i.e., between giving and taking away agency). This corroborates the companion species based work of post-humanists such as Bettany and Daly (2008), Fox (2006) and Haraway (2003).

In the context of consumers and their household pets, human subjects engage animal objects and animal subjects engage human subjects, whether this is in the co-creation of emotional experience as outlined above, or the inter-subjectivity of identity construction (integration) and classification or the reciprocity of play, which we shall now discuss in turn. 
Pet Ownership as Integration: The Inter-subjectivity of Identity Construction

In terms of animal subjects engaging human subjects, a number of our participants recalled their pets' ability to change either their mood or, indeed, their whole perspective on life. In this regard, when Alison was discussing a particular photograph of her dog Patsy, she informed us that "that was my screen saver at work and I knew if I was having a really horrible day and there were some horrible people asking horrible questions, I used to click on that and go aah" (Appendix 1b). Judith commented on getting "up in the morning feeling slightly jaded... and I'd open the door and she [Tessa] was always happy, always excited...it stops you getting totally bogged down in your own thoughts”. Similarly, Claire said, “you know life can have its ups and downs, but you start your day with Angus and it's like whoa! You know, spring is here". These instances seem to indicate that pets have a transformative power (Ahuvia 2005) on their owners. Since pets offer a "truly extraordinary or even magical" (Holbrook 1996, 150) presence in the lives of our participants, they may well transform their entire lives. This is perhaps best exemplified when participants tried to imagine their lives without their pets; Helen suggested "I can't imagine my house without an animal in it...it would seem empty". Similarly, Millie is of the view that "you feel more alone without a pet”. Sheila added, “I don't think your home is complete without one...when Edgar [previous cat] died, the house seemed to lose something”.

Since pets are able to exert such transformations in the lives of our participants, we would propose the additional practice of transforming (see Figure 2). This would help to encapsulate that the animal "acts upon...[and] moves" the human subject (Holbrook 1999, 11). This additional practice points to the possibility that for pet owners, at least, their identity is inter-subjectively constructed. Transforming practices and the inter-subjectivity of the pet owner identity is perhaps best illustrated by the stories our participants related about the behavior of their household pets. Similar to Holt's (1995) discussion of assimilating practices, 
a well-trained animal for many of our participants allowed them to construct their identities as competent participants within the social world of pet ownership.

Perhaps given the more acquiescent nature of dogs compared to cats, training was discussed mainly by our dog owners. That is not to say, that cats are better behaved than dogs; cat owners mentioned their cats stealing food and milk or lying somewhere they should not. Rather, it seemed that cat owners merely accepted their lack of control over their pets' behavior. Millie's acceptance was clearly evident - "unfortunately I know he does it [lies on top of the cooker] when we are not there, so I can't really stop him". Many dog-owning participants also commented on control aspects, particularly with regard to their dogs' obedience "lapses". For example, Mandy talked about how self conscious she felt when she described a particular photograph of Becca chewing her friend's expensive sheepskin rug - "I think it cost about eighty pounds and she was just chewing at it and everything...so Shirley wasn't best pleased" (Appendix 1c). Other behavioral lapses discussed occurred when their dogs "want to play with other dogs" or in response to a "running cat or a squirrel". In contrast to Bennett and Rohlf (2007), all our dog owners, with the exception of Judith, attended training classes with their dog. Claire did start off with a home-based training regime; but, on experiencing behavioral problems (e.g., barking, chasing other dogs, aggression), she decided to engage a one-to-one professional trainer for Angus. Gordon took Jake once to dog-training classes but he stopped going after the trainer "laughed and said I've never seen such an uncontrollable dog" (Jane). Despite feeling frustrated and humiliated by Becca - "I mean, it's embarrassing to have to go and retrieve her from across the playing field when you're shouting at her and she's not coming...you know it does make you feel a bit inadequate" - Mandy felt that "you've got to manage it...and having them trained is part of it". Consequently, Mandy commented that "now when we take her out she's generally very good and she does do what she's told". Claire was especially happy about the improvement in 
Angus' behavior particularly when this was noted by other dog owners they met on their walks.

In relation to producing and personalizing practices, a variety of practices were used by the participants to demonstrate their pet as a "constitutive element of their identity" (Holt 1995, 6). Here, Sheila and Tom who are committed heavy metal music fans were completely frank about imposing their heavy metal dress conventions upon the cats: "oh we put our personality on him...yeah...he (Bryan) normally has a brown leather one with studs in...Edgar [previous cat] had a heavy metal collar...they've nice collars". When pointing out that she did not "particularly" like "manufactured" looks in humans; Mandy intimated that she "wouldn't like to have a dog that...looked kind of manufactured in appearance...I'm afraid I don't have an inner chav ${ }^{3}$... to project onto the dog”. In agreement with Belk's (1988) aphorism, Sheila informed us that when she first met Tom he "already had a cat...it was a case of love me love my cat".

\section{Pet Ownership as Play: A Broader Interpretation of the Metaphor}

Although we found evidence in support of Holt's communing and socializing practices, a much more common theme referred to by our participants was that of literal play. All of our participants talked animatedly about larking around with their pets. These playbased activities embraced a variety of playthings ranging from chasing wild animals, the use of mundane items such as paper-bags and cardboard boxes to commercially produced toys. In order to address the need for literal play in this context including play between animals (see Rooney, Bradshaw and Robinson 2000) and reciprocal play between animals and their owners, we propose an additional practice, namely larking (see Figure 2).

While not widely discussed in the literature (exceptions being Haraway 2003; Holbrook 1996; Holbrook et al. 2001; Sanders 2003), reciprocal play between humans and animals is clearly an important aspect of pet ownership. Moreover, larking practices are often 
instigated by the pet rather than the human. Simon showed us this photograph and explained, “that's him $[\mathrm{DJ}]$ just putting his toy on the table...he wants me to play a game with him. So I put it in different places like the top of the telly or window sill and we have this game to see how long it is before he finds it...he doesn't take long” (Appendix 1d). Similarly, Mandy mentioned how Becca "loves to play and jumps up a lot - so if you're just trying to watch the telly, she can be a bit of a pest...she never wants to just sit and be stroked or anything". Finally, Judith and Nathan also talk about how Tessa likes us to "chase her round the garden. She won't go and fetch something and bring it back...what she wants is to get something and for you to want to take it off her and chase her" (Appendix 1e).

Stewart notes specific differences between his two cats regarding their preferences for larking around with toys - "you can buy stuff for them and she [Agatha] doesn't bother...but he'll [Brady] play with them. He'll play with them to a certain extent till I start winning [then] he gives up”. Here, Stewart's description of Brady's competitive behavior is similar to the conclusion reached by Rooney, Bradshaw and Robinson (2000) who note that play between humans and animals is less competitive than that between animals. In fact, competing is an additional practice proposed for inclusion in Holt's (1995) typology by Groves, Charter and Reynolds (2000) in their study of wine consumption. These authors argue that "whereas communing and socialising seek to draw people closer, competing is an interactive process which serves to distinguish the consumer from those around" (2000, 218). Clearly, this practice is relevant to the context of pet ownership; especially the competitive arena of cat and dog shows (Bettany and Daly 2008; Hirschman 1994). However, in comparison to this competitive context, the nature of competition between Stewart and Brady as described above appears to be more in tune with Grayson's (1999) notion of competition as a form of playing and having fun. While we recognize the massive interest in competitive cat and dog shows across the UK, only Sheila and Helen spoke of competing at animal shows and this was discussed as a previous rather than current interest. Given the relevance of competing 
practices to this context, we support Groves, Charter and Reynolds's (2000) extension to Holt's (1995) consuming-as-play metaphor and therefore include the additional practice of competing in Figure 2.

Overall, our participants' stories uniquely demonstrate the nuances and the complexity of play between humans and animals. When examined through the lens of our reworking of Holt's typology, it is evident that this metaphor is now able to capture the instances of reciprocal play between pets and their owners. Moreover, with the additional practice of larking and our endorsement of Groves, Charter and Reynolds' (2000) suggested practice of competing, the typology better explains the circumstances of literal play and competitive play, both between owners and their pets and among pets.

\section{Pet Ownership as Classification: Objects, Actions and Moral Values}

Alison described certain dog owners that she had seen on the beach as "not the usual dog walkers. I mean, normally on a cold day at the beach you get somebody wearing a pair of wellies, a woolly hat, gloves...the designer ones will be there in their sort of pink Wellingtons and designer outfits ' $n$ ' the dog looks immaculate - yeah, very different people". She questioned the motives of these owners and suggested that in general she felt that they were not "getting a dog for family reasons...they're not getting it to enhance their lives in any way...they are just getting it as a fashion accessory”. Thus, she seemingly likens these owners to the extrinsically motivated pet owners described in Beverland, Farrelly and Lim's (2008) study. In so doing her comments hint at something that is not easily captured by Holt's consuming-as-classification metaphor, namely the underlying moral dimensions of consumption.

In our literature section, we argued that a clear opportunity exists to extend the consuming-as-classification metaphor to embrace the personal, social and cultural values (see Heisley and Cours 2007) of being an animal's caretaker and companion. Thus we suggest that 
the consuming-as-classification metaphor ought to be broadened in order to capture the fact that consumers classify themselves and one another via objects, actions and values (see Figure 2).

In comparison to the cat owners, dog owners were more likely to "classify themselves in relation to relevant others" (Holt 1995, 10). For example, Nathan revealed that he viewed some dog owners differently, classifying certain types as "one of us". However, for the most part, classifying dog owners via the consumption object itself (i.e. breed of dog) led to value judgments on image and status. In this regard, Nathan referred to having a chocolate Labrador as being "just like having a Ferrari or a Porsche".

Continuing with the focus on the consumption object itself, most participants did not express a strong preference for purebred pets and of the few who currently own purebred animals some attributed their selection to that of their partner. Judith and Nathan expressed a preference for cross-breeds and felt "good" about the fact that they walked through an affluent "estate with obviously something that isn't anything and a bit scruffy". We suggest that the desire to distance themselves from people who own pedigrees for the purpose of using them as fashion accessories or status symbols, reflects an underlying moral judgment that such owners consider the needs of pets to be secondary to their own.

None of the participants owned a designer breed or hybrid; although both Claire and Mandy had initially considered the Labradoodle breed for hypoallergenic reasons. Claire decided against it, settling instead on a Standard Poodle as this equally minimized her allergies and Mandy changed her mind on seeing them: "We looked at more websites and some of them just looked like big perms really...they looked awful...utterly ridiculous”. Other participants were more explicit in terms of their unease with regard to animal-breed manipulation. For example, while Helen talked enthusiastically about her preference for the Abyssinian breed, as they were "quite normal...and had a pretty face" (Appendix 1f), she 
expressed disapproval of the growing intervention of breeders meddling to produce cats' faces that were "shoved out or pushed in".

With regard to classifying via actions, our participants did not engage in any form of what Arluke (2003) refers to as the "dark side of human-animal relations" and many of them ridiculed the idea of dressing animals in clothes. For example, Mandy told us that when she saw that her friends had dressed their dog in a neckerchief, she thought that "it looked very odd", while Sheila stated vociferously "no...you couldn't do that to them [i.e. dressing up], that's cruel'. Instead, with regard to the practices of grooming or accessorizing pets, our participants preferred their pets to look natural. Both Helen and Millie spoke of their preference for not putting collars on their cats. Helen's rationale was more about preserving the animal's appearance in that "these Abyssinian cats...they are not supposed to have a collar mark". However, Millie's motivation was that she preferred "them in their natural state”.

Sheila and Helen were the only participants to have experienced "affiliation" (Holt $1995,10)$ via the action of partaking in animal shows. However, Helen described the experience as being more of her late husband's "scene... he really wanted to have a show animal" and that it wasn't really her "cup of tea". Sheila did dog walking and dog agility activities with her neighbor's dogs while growing up - "one of them was a Crufts ${ }^{4}$ winner, they really were top dogs" but subsequently attributed her current indifference to a lack of time and that 'Marmelstein' was a pet rather than an object of "avocation" (Hirschman 1994, 617). Indeed, most of our participants expressed anti-avocation views. Alison felt very strongly that "people who show any animal...they've just got that complete, obsessed passion for whichever breed or whichever animal and Patsy is just a pet...we've got no want or need to show her at all, she is just our family pet”.

These findings demonstrate that pets play an extremely important part in the lives of our participants and, in corroboration of what Weston has suggested previously, "with their 
presence, increasingly come moral questions" $(2001,346)$. Overall, it is evident that our participants hold values with respect to the moral consequences of behavior in relation to pets. As the UK affords greater legal protection to animals than that offered by the USA or any other European country, this finding is perhaps not that surprising as the "social and cultural context in which individuals are immersed determines, in large part, the values, attitudes and fundamental beliefs they embrace" (Isaacs 2001, 147). Thus, in addition to classifying through objects and actions, it is clear that consumers also classify through values. However, in contrast to Beverland, Farrelly and Lim's $(2008,490)$ research, for those of our participants who did show an initial interest in purchasing a designer hybrid (i.e., a Labradoodle), this "was not indicative of a society that loves labels", so much as selecting a breed of dog that does not have an adverse effect upon their health. This suggests that in some situations human needs supersede the potential animal welfare implications of breed manipulation. As mentioned in the section on pet ownership as integration, we see once again evidence of pet owners oscillating between treating pets as equals and relegating them to the status of animals.

\section{Conclusions \& Avenues for Future Research}

It is clear that the context of human-animal relationships does indeed provide a rich consumption context by means of which to advance consumer-culture theory (Brownlie 2008). Taking our extensions to Holt's (1995) typology derived in this context in turn, we first acknowledge the oscillation between subject-object and subject-subject relations in the process of consumption. As our previous analysis indicates, consumers are inconsistent in their dealings with consumption objects. That is, they appear to vacillate between treating consumption objects as objects and interacting with them as subjects. This addition serves to illuminate the unstable relationships between consumers and consumption objects and thereby develops Holt's typology beyond its previous consumer-centric conceptualization. 
Second, and in so doing, we identify the additional practices of: transforming in relation to identity construction; larking which recognizes the mutuality of literal play between consumer and consumption object; and classification through moral values. We also endorse Groves, Charter and Reynolds's (2000) suggestion of competing practices.

Consumer centric conceptualizations of consumption acknowledge that consumers are able to transform consumption objects through consumer rituals such as possession, exchange or divestment rituals (McCracken 1990). However, transforming practices elucidate the fluidity and ambiguity of the relationships between consumers and consumption objects. They do so by reframing attention so as to recognize instances in which "the situation is reversed" and the consumption object simultaneously "acts upon" or "moves" the consumer (Holbrook $1999,11)$. Our analysis above demonstrated quite clearly that both consumers and consumption objects have the ability to mutually transform the identity of one another.

Larking practices provide further examples of the ways in which consumption objects act upon consumers. In the context of our study, pets induced humans to engage in literal play as much as, if not more so than the other way round. Thus, by drawing attention to the agency of non-human objects, larking practices highlight the complex nature of the social dynamics between consumers and consumption objects.

Finally, it is evident that consumers hold values with respect to the moral consequences of their behavior. Therefore, in addition to using objects and actions to classify themselves and others, consumers also classify through moral values. Certainly within the context of pets, our analysis revealed that consumers considered the effects of breed manipulation and shunned the dressing-up and excessive grooming of pets. Thus, by incorporating the practice of classifying through values, the consuming as classification metaphor now embraces the personal, social and/or cultural values present within the relationships between consumers and consumption objects. 
With regard to the implications of this study for future cultural studies of humananimal relations, our findings clearly demonstrate the agency of pets either through their reciprocal loving relationships or their instigating playful activities. Thus, our research provides additional empirical evidence that challenges the Cartesian notion of the humananimal divide and further contributes towards undermining the treatment of animals as “other". That said pet owners clearly vacillate between treating their pets as equals and treating them as "other", a circumstance that we would suggest warrants further investigation and analysis. While we humans already bestow moral considerations on pets such as cats and dogs (albeit that our study shows this is done rather flexibly), these considerations do not always extend to other pets such as reptiles and fish, never mind to other animal categories such as farm animals. It is this issue that needs to be addressed if we are to place our relations with all animals on an equal footing.

Since animals can and do exhort humans to act, this suggests that the relations between the two are truly reciprocal. Acknowledging this reciprocity serves to disrupt the categorical boundary between humans and animals. If we relinquish the boundary between humans and animals then we accept the relational ontology of the social, a conception that challenges the notion of the fundamental essence of all things, including the foundational human subject. Our study of human-animal relations suggests that analyzing consumption from the perspective of the foundational human subject and his or her emotional experience, use, and manipulation of consumption objects obscures the manifold ways in which consumers and consumption objects co-construct the experiences and meanings of consumption. Thus, our findings corroborate Zwick and Dholakia's (2006: 32) assertions regarding the "mutually reinforcing and enduring sociality" that binds consumers and epistemic consumption objects as well as lending support to Borgerson's (1995) insightful analysis of the contributions that Daniel Miller's theory of materiality brings to the analysis of consumption within the discipline of consumer research. If we concede that consumers and 
consumption objects are performed through their interactions in a complex network of heterogeneous materials, to use the parlance of actor-network theory, then we begin to appreciate that the experiences and meanings of consumption are continuously in process and inherently unstable. The challenge is in fathoming ways to analyze the dynamic instability of consumption and we suggest that our extensions to Holt's (1995) typology contribute to this endeavor.

If we take these extensions and consider them in the context of baseball, where Holt (1995) initially developed the typology, it is reasonable to suggest that both spectators (consumers) and baseball teams (producers) co-construct the sporting experience thereby exemplifying the new dominant logic of marketing (Peñaloza and Venkatesh 2006; Vargo and Lusch 2004). Moreover, we would argue that like other sports people, musicians, actors and celebrities, the list goes on, baseball players are in a reciprocal, if not loving then certainly highly emotional, relationship with their fans in which they enjoy, perhaps for some, even need the adoration of their fans in order to perform their best.

Thus, with regard to transforming practices, when the baseball team is performing well this undoubtedly leads to a tremendous feel-good factor among the fan base, perhaps transforming some fans from the status of being either 'temporary' or 'local' to 'devoted' or even 'fanatical' (Hunt, Bristol and Bashaw 1999). Similarly a highly supportive fan base will likely spur the team on to perform better. Of course the co-creation of experiences and meanings is not limited to consumption objects involving human performances only; Cheetham's (2009) analysis of the disposal of objects at auction indicates that inanimate objects also exert a form of social agency on prospective owners. Moreover, Belk's (2003) study demonstrates that objects as potentially mundane as shoes are able to transform the identity of their owners.

Returning to baseball and other sporting events, in terms of larking practices, we see the camaraderie between players and fans in a variety of practices including the variously 
named Wave or Mexican Wave performed by fans at a range of stadium events, the dances and gymnastics performed by football players directly to the fans following scoring a goal and the charity work of baseball players such as Curt Schilling and footballers such as David Beckham to encourage young children into sports. Competing practices are also observed throughout baseball and football when for example fans heckle opposition players in order to distract/impact on their performance or when opposition players taunt the home fans when winning. The supporters of the San Francisco Giants are renowned for heckling the left field of the opposing team to influence results. A football game between rivals Manchester City Football Club and Manchester United Football Club will often involve players celebrating a goal at the opponents end, pointing to the club crest/shirt, thus instigating and maintaining a fervent sense of competitive rivalry between the fans and opposing teams.

Finally with regard to classification through moral values, baseball fans may be tempted to withdraw their support for players and teams due to the morally inappropriate behavior of players both on the pitch (aggressive behavior towards opponents, cheating by taking performance enhancing drugs) and off the pitch (sex scandals, alcohol and/or drug induced brawls). Among the fan base itself, we can also envisage instances of the intrinsically motivated sports fan who supports their team through thick and thin looking disparagingly at the extrinsically motivated sports fan who switches allegiance when the chips are down.

When taken with the ten practices that Holt (1995) identifies, altogether these fourteen consumption practices are likely to illuminate consumption in a wide variety of contexts beyond baseball and the other examples mentioned thus far from epistemic consumption objects such as on-line investing to virtual gaming worlds such as Second Life and the World of Warcraft. Here, we can certainly envisage larking (i.e. literal play), competing and, in the current climate perhaps increasingly so, classification through moral values, permeating the co-constructed experiences and meanings of consumption in these contexts. However, in 
order to investigate these practices more fully we would suggest that future research needs to focus on producers as well as consumers.

\section{Acknowledgements}

The authors gratefully acknowledge the extremely valuable comments and suggestions from Professor Lisa Peñaloza, Professor Morris Holbrook and the two anonymous reviewers.

\section{Notes}

[1] Holbrook's Typology of Consumer Value is outlined in Holbrook (1994) and developed in Holbrook (1999).

[2] Note that pseudonyms are adopted when referring to participants throughout the remainder of this paper.

[3] Chav is English slang used to describe less educated people; a person from a lower class; or a person with poor taste mainly in reference to conspicuous dress codes and large items of gold jewelry.

[4] Crufts is the world's largest dog show which takes place annually in the UK (see http://www.crufts.org.uk/ ).

\section{References}

AC Nielsen EDI. 2007. Highest Grossing Films in the UK http://www.prnewswire.co/uk/cgi/news/release?id=50678.

Ahuvia, Aaron, C. 2005. Beyond the Extended Self: Loved Objects and Consumers' Identity Narratives. Journal of Consumer Research 32(June): 171-184.

Allen, Douglas, E. and Elton, G. McGoun. 2000. Hedonic Investment. Financial Services Review 9: 389-403.

Arluke, Arnold. 2003. Ethnozoology and the Future of Sociology. International Journal of Sociology and Social Policy 23 (3): 26-45.

Arnould, Eric, J. and Craig, J. Thompson. 2005. Consumer Culture Theory (CCT): Twenty Years of Research. Journal of Consumer Research 31(March): 868-882.

Aylesworth, Andrew, Ken Chapman and Susan Dobscha. 1999. Animal Companions and Marketing: Dogs are More Than Just a Cell in the BCG Matrix. In Advances in Consumer Research 26, 385-391.

Belk, Russell, W. 1988. Possessions and the Extended Self. Journal of Consumer Research 15: 139-168.

Belk, Russell, W. 1996. Metaphoric Relationship with Pets. Society \& Animals: Journal of Human-Animal Studies 4 (2): 121-145.

Belk, Russell, W. 2003. Shoes and the Self. Advances in Consumer Research 39: 27-33.

Bennett, Pauleen, C. and Vanessa, I. Rohlf. 2007. Owner-Companion Dog Interactions: Relationships Between Demographic Variables, Potentially Problematic Behaviours, Training Engagement and Shared Activities. Applied Animal Behaviour Science 102: 65-84.

Bettany, Shona and Daly, Rory. 2008. Figuring Companion-Species Consumption: A MultiSite Ethnography of the Post-Canine Afghan Hound. Journal of Business Research 61 (5): 408-418.

Beverland, Michael B., Francis Farrelly and Elison, A. Ching Lim. 2008. Exploring the Dark Side of Pet Ownership: Status-and-Control-Based Pet Consumption. Journal of Business Research 61 (5): 490-496. 
Borgerson, Janet. 2005. Materiality, Agency, and the Constitution of Consuming Subjects: Insights for Consumer Research, Advances in Consumer Research, 32: 439-443.

Brownlie, Douglas. 2008. Relationship Climate Canaries: A Commentary Mosteller (2007) Inspires. Journal of Business Research 61 (5): 522-524.

Callon, Michel. 1986. Some Elements of a Sociology of Translation: Domestication of the Scallops and the Fishermen of St. Brieuc Bay. In Power, Action and Belief. A New Sociology of Knowledge? edited by John Law, London: Routledge and Kegan Paul, 196-233.

Cavanaugh, Lisa, A., Hillary, A. Leonard and Debra, L. Scammon. 2008. A Tail of Two Personalities: How Canine Companions Shape Relationships and Well-Being. Journal of Business Research 61 5: 469-479.

Cheetham, Fiona. 2009. Out of Control? An Ethnographic Analysis of the Disposal of Collectable Objects through Auction. Journal of Consumer Behaviour. 8(6): 316-326.

Collier, John Jr. 1967. Visual Anthropology: Photography as a Research Method, New York: Holt, Rhinehart \& Winston.

Dotson, Michael, J. and Eva, M. Hyatt. 2008. Understanding Dog-Human Consumption,” Journal of Business Research 61 (5): 457-466.

Firat, A. Fuat and Nikhilesh Dholakia. 2006. Theoretical and Philosophical Implications of Postmodern Debates: Some Challenges to Modern Marketing. Marketing Theory 6 (2): 123-162.

Fox, Rebekah. 2006. Animal Behaviours, Post-human Lives: Everyday Negotiations of the Animal-Human Divide in Pet-keeping. Social \& Cultural Geography 7 (4): 525-537.

Grayson, Kent. 1999. The Dangers and Opportunities of Playful Consumption. In Consumer Value: A Framework for Analysis and Research. Chapter 5, edited by Morris Holbrook. London: Routledge.

Greenebaum, Jessica. 2004. It's a Dog's Life: Elevating Status from Pet to Fur-Baby at Yappy Hour. Society and Animals 12 (2): 117-135.

Groves, R., S. Charters and C. Reynolds. 2000. Imbibing, Inscribing, Integrating and Imparting: A Taxonomy of Wine Consumption Practices. Journal of Wine Research 11 (3): 209-222.

Hall, E.W. 1961. Our Knowledge of Fact and Value. Chapel Hill: University of North Carolina Press.

Haraway, Donna. 2003. The Companion Species Manifesto: Dogs, People and Significant Otherness. Chicago: Prickly Paradigm Press.

Harker, Rachael M. and Glyn, M. Collis and June McNicholas. 2000. The Influence of Current Relationships Upon Pet Animal Acquisition. In Companion Animals \& Us, edited by Anthony L. Podberscek, Elizabeth Paul and James A. Serpell, Cambridge: Cambridge University Press, 189-208.

Heisley, Deborah, D. and Deborah Cours. 2007. Connectedness and Worthiness for the Embedded Self: A Material Culture Perspective. Consumption, Markets and Culture 10 (4): 425-450.

Heisley, Deborah, D. and Sidney, J. Levy. 1991. Autodriving: A Photoelicitation Technique. Journal of Consumer Research 18: 257-272.

Herzog, Harold, Bentley, Alexander, R. and Hahn, Matthew, W. (2004) "Random Drift and Large Shifts in Popularity of Dog Breeds," Proceedings of the Royal Society, Biology Letters Supplement, 271(5), August.

Hirschman, Elizabeth, C. 1994. Consumers and their Animal Companions. Journal of Consumer Research 20 (March): 616-632.

Holbrook, Morris, B. 1994. The Nature of Customer Value: An Axiology of Services in the Consumption Experience. In Service Quality: New Directions in Theory and Practice, edited by Roland T. Rust and Richard L. Oliver, London: Sage Publications. 
Holbrook, Morris, B. 1996. Reflections on Rocky. Society \& Animals: Journal of HumanAnimal Studies 4 (2): 147-168.

Holbrook, Morris, B. 1997. Feline Consumption, Ethnography, Felologies and Unobtrusive Participation in the Life of a Cat. European Journal of Marketing 31 (3/4): 214-233.

Holbrook, Morris, B. 1999. Introduction to Consumer Value. In Consumer Value: A Framework for Analysis and Research. Chapter 1, edited by Morris Holbrook. London: Routledge.

Holbrook, Morris, B., Debra, L. Stephens, Ellen Day, Sarah M. Holbrook and Gregor Strazar. 2001. A Collective Stereographic Photo Essay on Key Aspects of Animal Companionship: The Truth About Dogs and Cats," Academy of Marketing Science Review, [on-line@www.amsrev.org (www. Amsreview.org/amsrev/theory/holbrook01-01.html)].

Holbrook, Morris, B. and Arch, G. Woodside. 2008. Animal Companions, Consumption Experiences and the Marketing of Pets: Transcending Boundaries in the AnimalHuman Distinction. Journal of Business Research 61 (5): 377-381.

Holt, Douglas, B. 1995. How Consumers Consume: A Typology of Consumption Practices. Journal of Consumer Research 22 (June): 1-15.

Holt, Douglas, B. 1997. Poststructuralist Lifestyle Analysis: Conceptualizing the Social Patterning of Consumption in Postmodernity. Journal of Consumer Research 23 (March): 326-350.

Hunt, Kenneth, A., Terry Bristol, and R. Edward Bashaw. 1999. A Conceptual Approach to Classifying Sports Fans. Journal of Services Marketing 13(6): 439-452.

Isaacs, Tracy. 2001. Cultural Context and Moral Responsibility. In Business Ethics: Critical Perspectives on Business and Management, edited by Alan Malachowski, London: Routledge.

Knorr Cetina, K.D. 2001. Postsocial Relations: Theorizing Sociality in a Post-social Environment. In Handbook of Social Theory, edited by G. Ritzer and B. Smart. California: Sage.

Laurier, E., A. Whyte and K. Buckner. 2002. Neighbouring as an Occasioned Activity: Finding a Lost Cat. Space and Culture 5 (4): 346-367.

McCracken, Grant. 1988. The Long Interview. London: Sage Publications.

McCracken, Grant. 1990. Culture and Consumption: New Approaches to the Symbolic Character of Consumer Goods and Activities. Bloomington and Indianapolis: Indiana University Press.

McFall, Liz and Paul du Gay. 2001. Consuming Advertising: Consuming Cultural History. In The Changing Consumer: Markets and Meanings, edited by Steven Miles, Alison Anderson and Kevin Meethan, London: Routledge, 74-89.

McKechnie, Sally and Caroline Tynan. 2006. Social Meanings in Christmas Consumption: An Exploratory Study of UK Celebrants' Consumption Rituals. Journal of Consumer Behaviour 5 (March-April): 130-144.

Mick, David Glen and Michelle DeMoss. 1990. Self-Gifts: Phenomenological Insights from Four Contexts. Journal of Consumer Research 17 (December): 322-332.

Myers, Olin, E. 2003. No Longer the Lonely Species: A Post-Mead Perspective on Animals and Sociology. International Journal of Sociology and Social Policy 23 (3): 46-68.

Peñaloza, Liza. 2008. Moving From Subject-Object to Subject-Subject Relations: Comments on "Figuring Companion-Species Consumption". Journal of Business Research 61 (5): 419-421.

Peñaloza, Liza and Alladi Venkatesh. 2006. Further Evolving the New Dominant Logic of Marketing: From Services to the Social Construction of Markets. Marketing Theory 6 (3): 299-316. 
Prosser, Jon and Dona Schwartz. 1998. Photographs within the Sociological Research Process, In Prosser, Jon (Ed) Image-based Research: A Sourcebook for Qualitative Researchers, London: Falmer Press, pp. 115-130.

Rooney, Nicola J., John, W. Bradshaw and Ian, H. Robinson. 2000. A Comparison of DogDog and Dog-Human Play Behaviour. Applied Animal Behaviour Science 66 (June): 235-248.

Sanders, Clinton, R. 1990. The Animal 'Other': Self Definition, Social Identity and Companion Animals. In Advances in Consumer Research 17, 662-668.

Sanders, Clinton, R. 2003. Actions Speak Louder Than Words: Close Relationships Between Humans and Nonhuman Animals. Symbolic Interaction 26 (3): 405-426.

Stephens, Deborah, L. and Ronald, P. Hill. 1996. The Dispossession of Animal Companions: A Humanistic and Consumption Perspective. Society \& Animals: Journal of HumanAnimal Studies 4 (2): 189-210.

Taylor, Nicola. 2007. Human-Animal Studies: A Challenge to Social Boundaries. ProteusLjubljiana 24 (1): 1-4.

Thompson, Craig, J., William B. Locander and Howard R. Pollio. 1989. Putting Consumer Experience Back into Consumer Research: The Philosophy and Method of ExistentialPhenomenology. Journal of Consumer Research 16: 133- 146.

Vargo, Stephen, L. and Robert, F. Lusch. 2004. Evolving to a New Dominant Logic for Marketing. Journal of Marketing 68 (January): 1-17.

Warde, Alan. 2005. Consumption and Theories of Practice. Journal of Consumer Culture 5 (2): 131-153.

Weston, Anthony.: 2001, A $21^{\text {st }}$ Century Ethical Toolbox. Oxford: Oxford University Press.

Wood, Lisa, Billie Giles-Corti and Max K. Bulsara. 2005. The Pet Connection: Pets as a Conduit for Social Capital. Social Science \& Medicine 61: 1159-1173.

Wood, Lisa, J., Billie Giles-Corti, Max K. Bulsara and Darcy, A. Bosch. 2007. More Than a Furry Companion: The Ripple Effect of Companion Animals on Neighbourhood Interactions and Sense of Community. Society and Animals 15 (1): 43-56.

Zaltman, Gerald. and Robin H. Coulter. 1995. Seeing the Voice of the Customer: Metaphorbased Advertising Research. Journal of Advertising Research July/August: 35-51.

Zwick, Detlev and Nikhilesh Dholakia. 2006. The Epistemic Consumption Object and Postsocial Consumption: Expanding Consumer-Object Theory in Consumer Research. Consumption, Markets and Culture 9 (1): 17-43. 


\section{Appendix}

1 a) Reciprocal love: "That's Billy and that's my feet...I wanted to show that wherever I am is a good place to find him" (Millie)

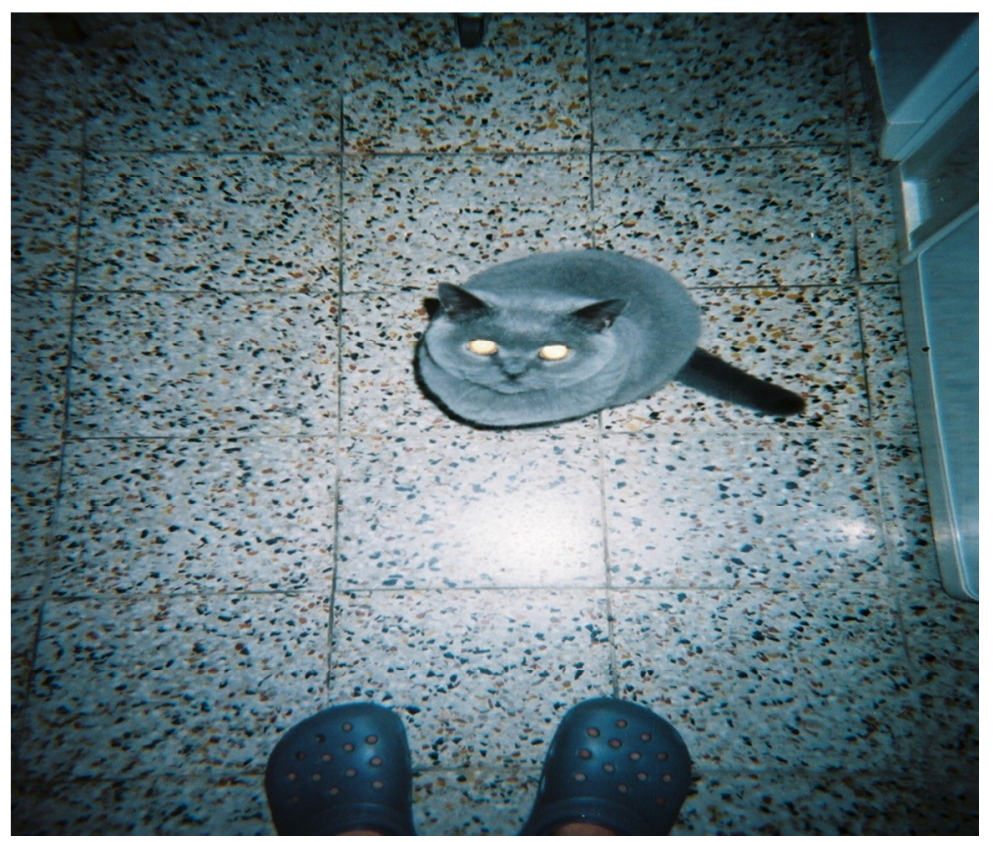

1 b) Transformative power of pets: Alison's screensaver which helps to transform her "horrible" days at work

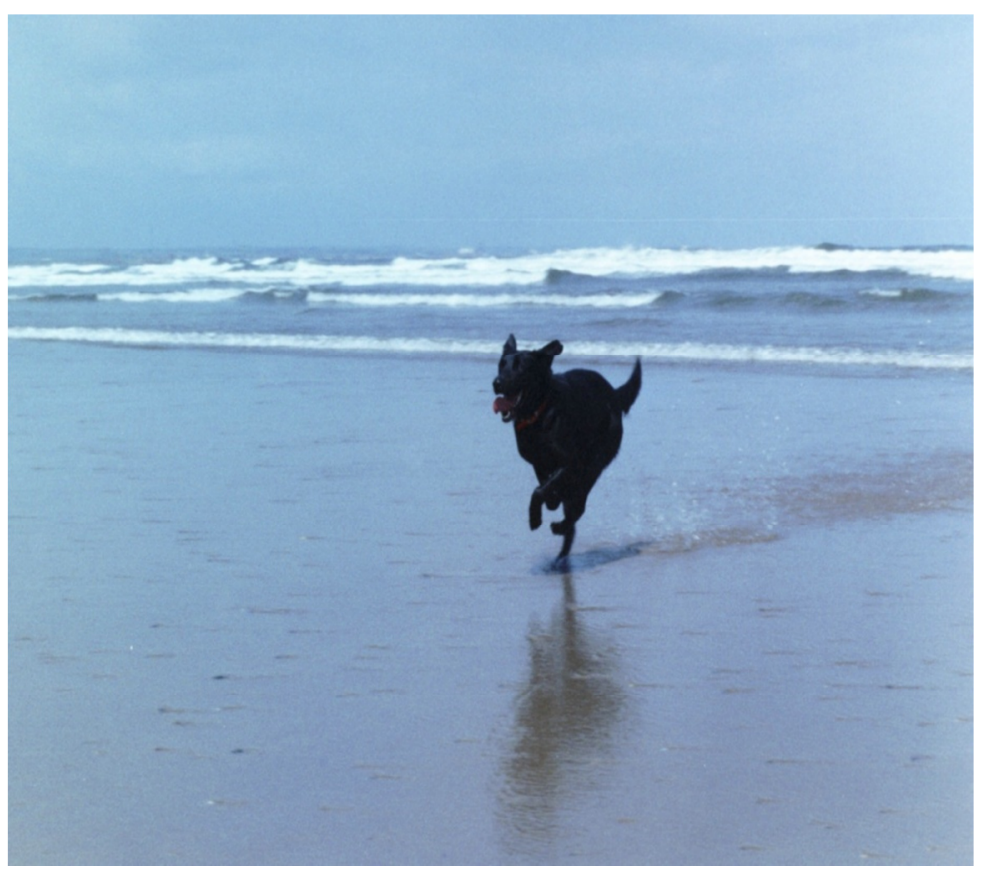


1 c) Pet owner identity and the untrained animal: "She was just having a ball...chewing at it and everything" (Mandy)

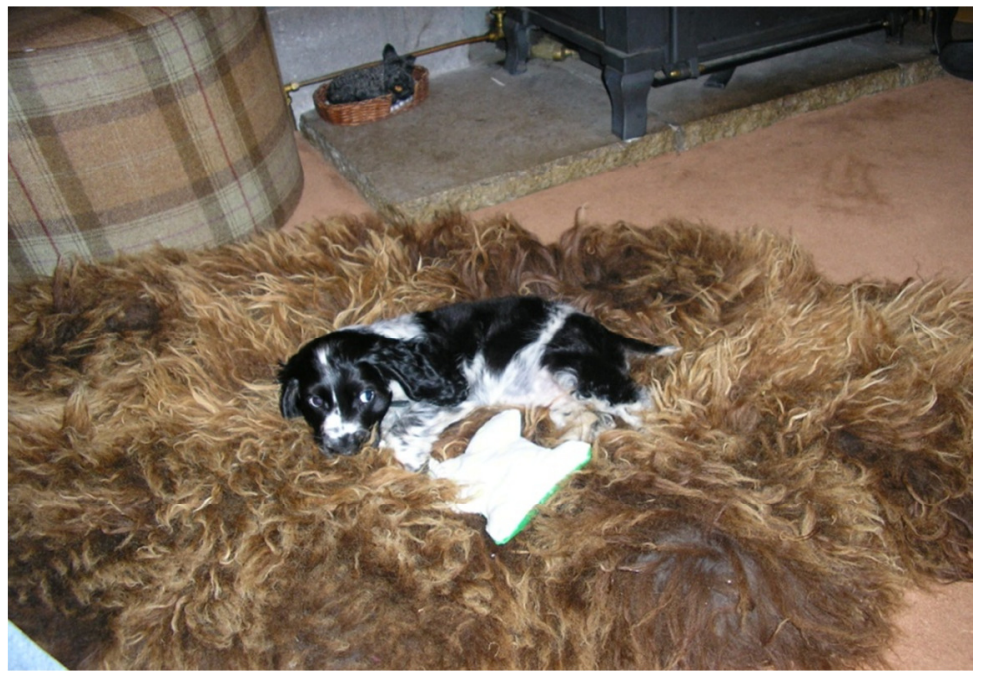

1 d) Reciprocal play: DJ instigating play with Simon - "that's him just putting his toy on the table...he wants me to play a game with him"

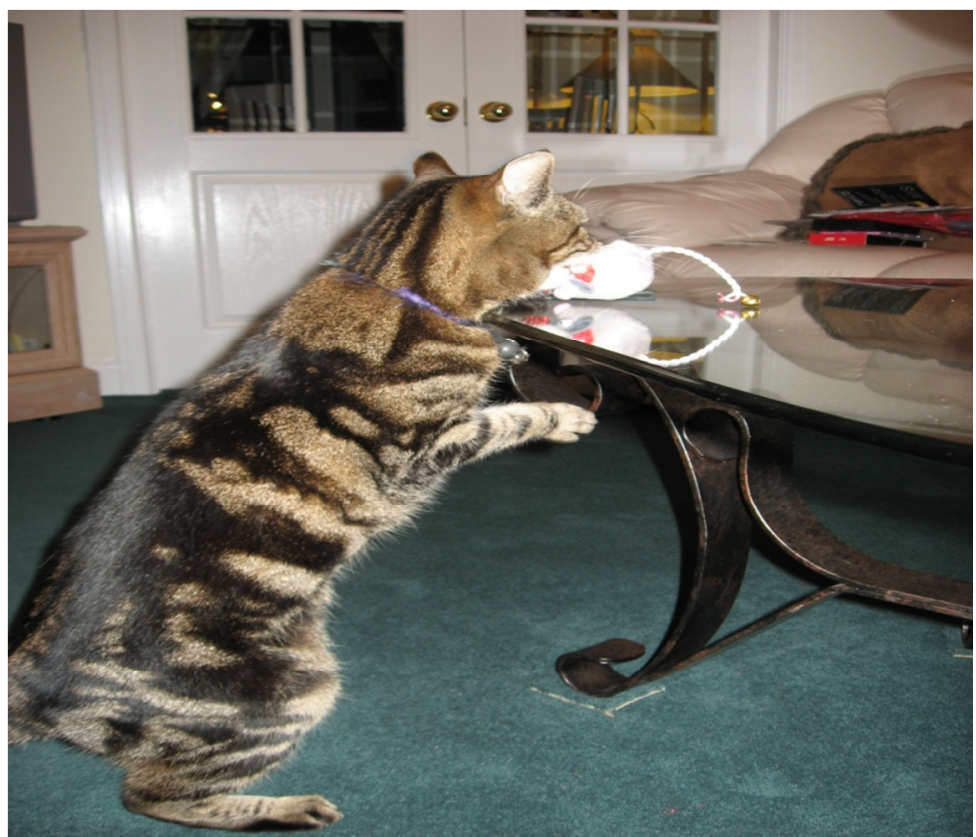


1 e) Reciprocal play: Tessa and her rubber ring - "what she wants is to get something and for you to want to take it off her and chase her" (Judith)

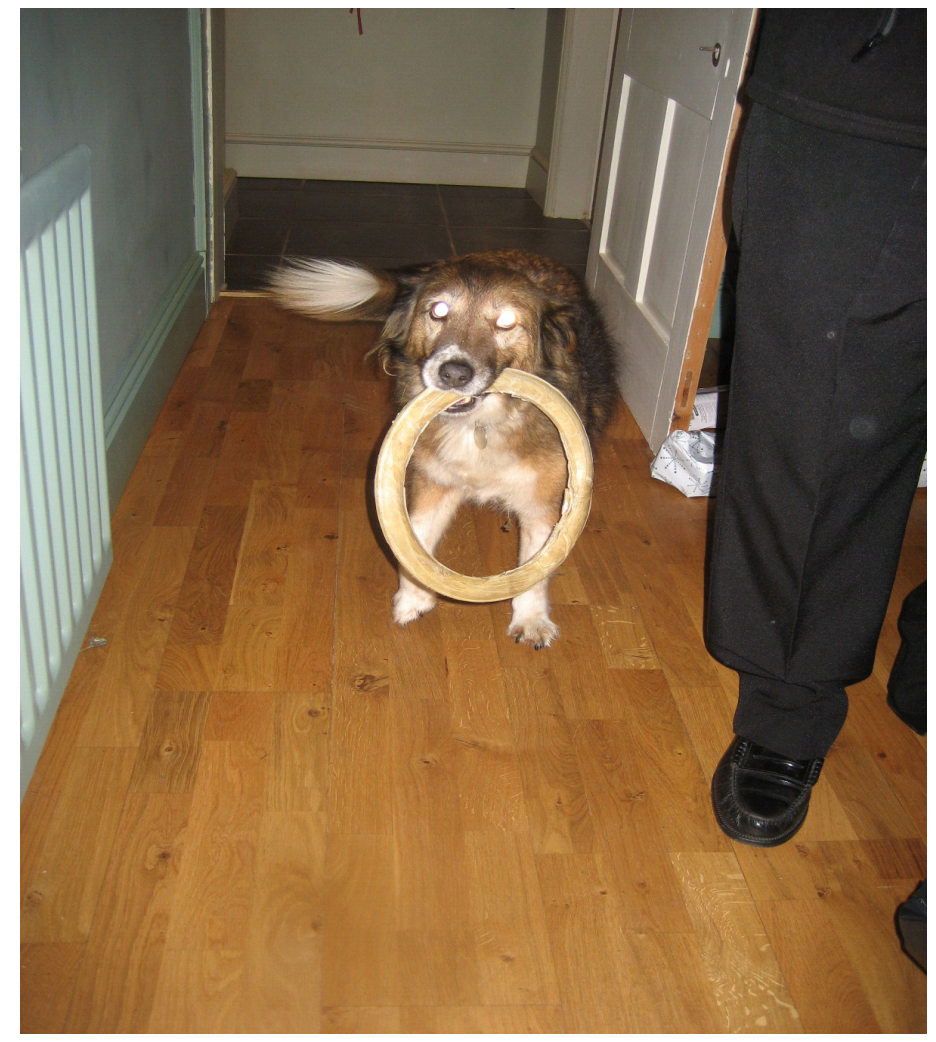

1 f) Moral dimension: Helen's moral judgment regarding the Abyssinian breed "quite normal...not shoved out or pushed in"

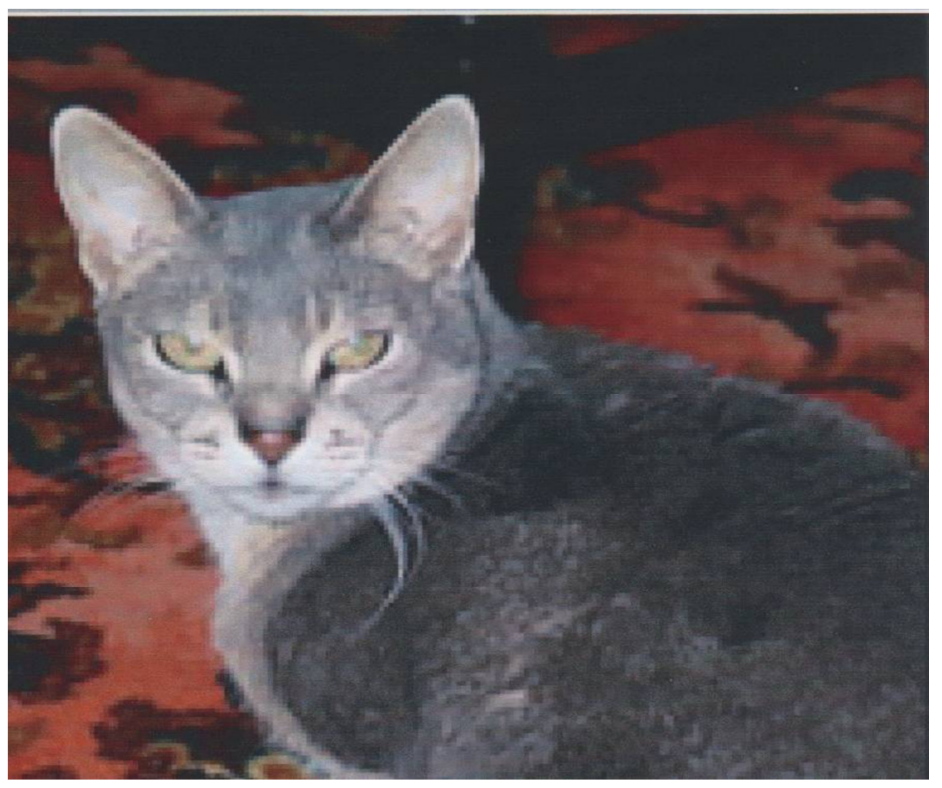


Figure 1 Metaphors for Consuming and Consumption Practices

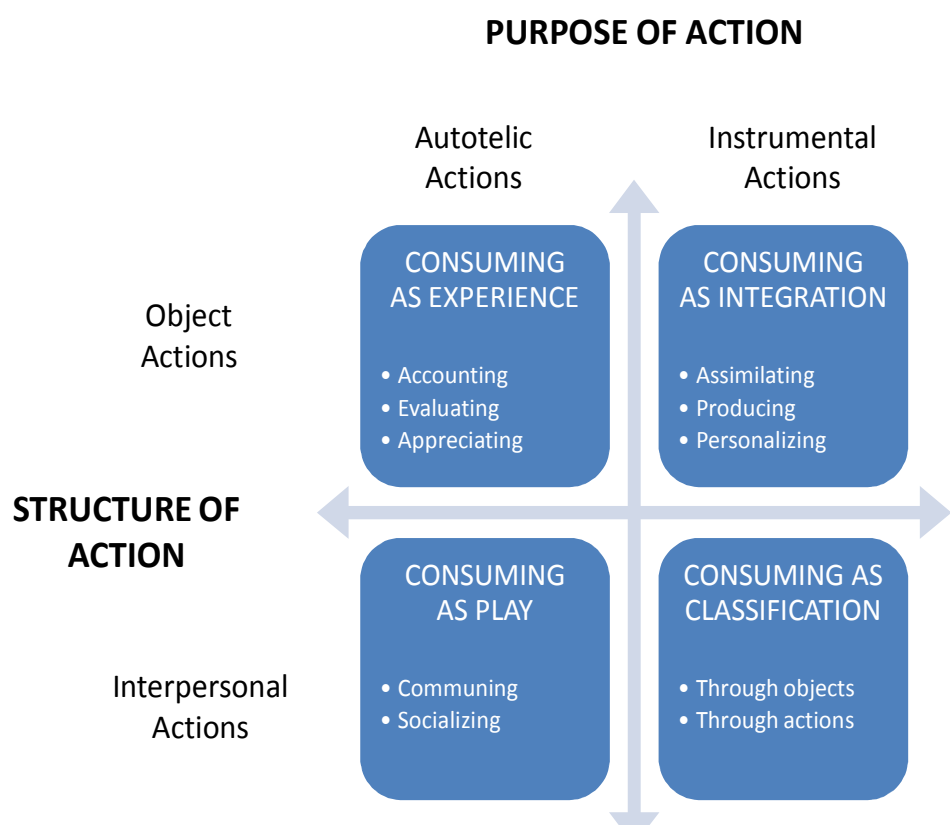

Source: Adapted from Holt $(1995,3)$ 
Figure 2 Metaphors for Consuming and Consumption Practices in the Context of Pet Ownership

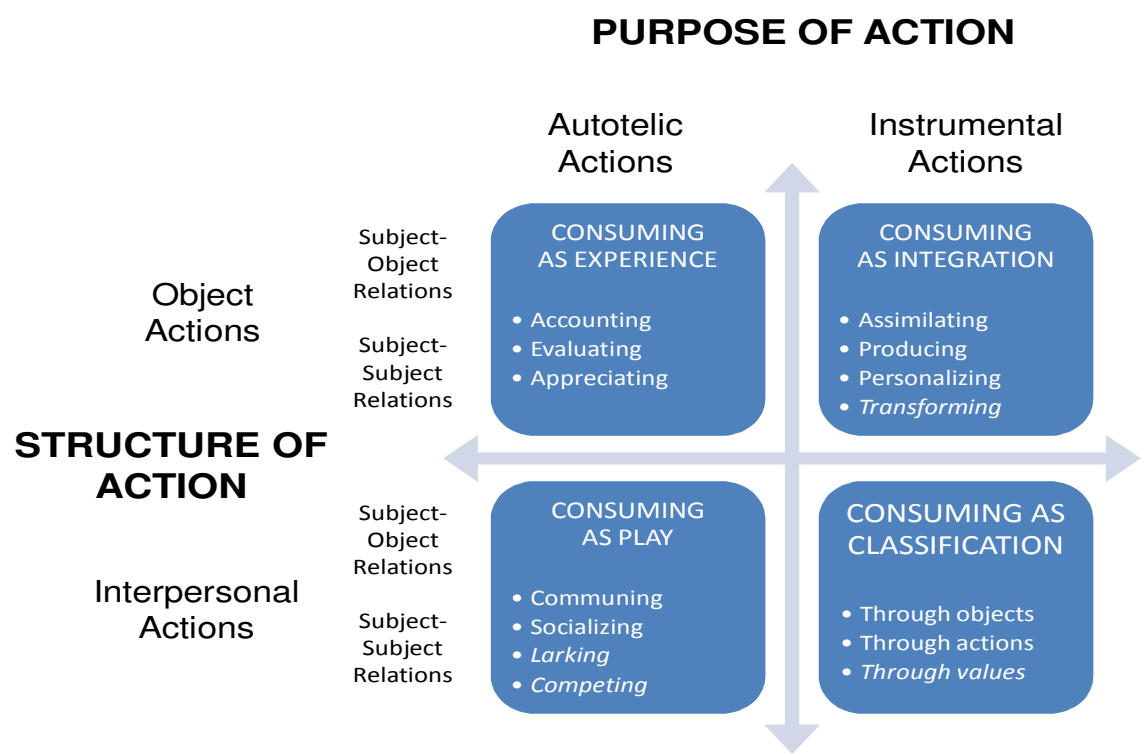

Source: $\quad$ Adapted from Holt (1995, 3), Holbrook (1994, 1999), Groves, Charters and Reynolds (2000) and Heisley and Cours (2007).

*Note our proposed extensions are highlighted in italics. 